Fanum

Sociológico

\section{Forum Sociológico}

Série II

$27 \mid 2015$

Mobilidade científica \& imigração qualificada

\title{
Estudo exploratório sobre racionalidades leigas de saúde e doença mental em Maputo e João Pessoa
}

\section{Bárbara Bäckström}

\section{(2) OpenEdition \\ 1 Journals}

\section{Edição electrónica}

URL: https://journals.openedition.org/sociologico/1317

DOI: 10.4000/sociologico.1317

ISSN: 2182-7427

\section{Editora}

CICS.NOVA - Centro Interdisciplinar de Ciências Sociais da Universidade Nova de Lisboa

\section{Edição impressa}

Data de publição: 21 dezembro 2015

Paginação: 87-95

ISSN: 0872-8380

\section{Refêrencia eletrónica}

Bárbara Bäckström, «Estudo exploratório sobre racionalidades leigas de saúde e doença mental em Maputo e João Pessoa», Forum Sociológico [Online], 27 | 2015, posto online no dia 28 maio 2016, consultado o 31 março 2022. URL: http://journals.openedition.org/sociologico/1317 ; DOI: https:// doi.org/10.4000/sociologico.1317 


\title{
ESTUDO EXPLORATÓRIO SOBRE RACIONALIDADES LEIGAS DE SAÚDE E DOENÇA MENTAL EM MAPUTO E JOÃO PESSOA*
}

\author{
Bárbara Bäckström \\ Universidade Aberta, Departamento de Ciências Sociais e de Gestão \& Centro de Estudos das Migrações e das Relações \\ Interculturais (CEMRI)
}

\section{Introdução e enquadramento do estudo}

A atividade de pesquisa foi desenvolvida no âmbito do Centro de Estudos das Migrações e das Relações Interculturais/CEMRI - FCT e Universidade Aberta. Na sequência de pesquisas anteriores desenvolvidas na área das migrações, interculturalidades, saúde e bem-estar, pretendemos aprofundar o conhecimento sobre as racionalidades e protagonismos de saúde e doença em contextos interculturais diversos. Neste sentido, implementámos um projeto de análise comparativa de racionalidades e tipos de adoecimento junto de moçambicanos e brasileiros. Pretendemos igualmente compreender as racionalidades leigas de saúde e doença (física e mental), enquanto instrumentos heurísticos de discussão da sociedade e da cultura, procurando os seus significados sociais e culturais que se inscrevem nas trajetórias de cuidado mobilizadas pelas populações, onde, a par da medicina oficial biomédica, são mobilizadas outras medicinas (tradicionais/populares e alternativas). Neste contexto pretende-se ainda mapear racionalidades e formas de conceber e agir no campo da saúde e informar as políticas e a organização de serviços, a formação de profissionais, e contribuir para o avanço da ciência social da saúde e interculturalidades e para a integralidade em saúde.

O estudo assenta na premissa de que os significados associados à loucura e à doença mental, experienciada ou não, são construções socioculturais em que o conhecimento científico da medicina se interpenetra com o saber popular para a produção de sentido. Esses significados sociais manifestam um "acordo" que num determinado tempo e espaço se estabelece numa determinada sociedade. São, por isso mesmo, relativos - o que é loucura e doença mental numa sociedade pode não o ser noutra. Com este estudo pretende-se perceber como é que a população identifica, concebe, explica e lida com a loucura, em geral, e com a doença mental, em particular, e de que modo recorre à medicina tradicional com o propósito de pedir auxílio neste campo. O saber leigo sobre saúde e doença relaciona-se intimamente com o estudo das causas que as pessoas atribuem à doença, na tentativa de lhe conferir sentidos. Compreender as causas é uma preocupação central de quem experiencia a doença.

O objetivo geral deste estudo é entender a forma como um grupo restrito da população adulta perceciona e explica o sofrimento mental e, por outro lado, perceber a relação entre a medicina tradicional e a saúde mental. Os objetivos específicos que se prendem com os objetivos gerais são os seguintes: conhecer o discurso leigo acerca da saúde mental e acerca da medicina tradicional por parte de um grupo restrito de adultos da população em geral; conhecer o discurso oficial sobre as questões quer da saúde mental, quer da medicina tradicional, por parte dos dirigentes e de alguns profissionais de ambas as áreas. Focámo-nos essencialmente nas seguintes questões: como as pessoas leigas percecionam e explicam o sofrimento mental e a doença mental, o que se entende por racionalidades de saúde e doença mental, que uso fazem da medicina tradicional ou das práticas complementares e alternativas para lidar com saúde mental e a doença mental, o recurso à medicina tradicional, recurso às igrejas e centros espíritas e recurso às medicinas integrativas e complementares e qual o discurso de dirigentes e profissionais de saúde mental.

Partimos para o terreno com as hipóteses da existência de um pluralismo dos sistemas de cuidados para lidar com a doença (Kleinman, 1984) e de que as diversidades culturais, o habitus e referências culturais podem colocar-nos perante sistemas explicativos diferentes e perante sistemas de cuidados diferentes, relacionando-se com vários fatores.

Nos dois terrenos procurámos contextualizar esta problemática, de forma a entender a evolução histórica, identificar as políticas de saúde mental e os seus impactos na prática (documentação legislativa). De igual forma procedemos a um levantamento e

* Este estudo tem por base o estudo anterior de Alves F. (2010 e 2011) que colaborou neste projeto no desenho da pesquisa, definição da problemática, enquadramento do estudo, definição dos instrumentos de recolha de dados, a quem dirijo um especial agradecimento. 
mapeamento das principais instituições formais e informais que prestam apoio na área da saúde/ /doença mental em Maputo e em João Pessoa, ao nível da medicina convencional e das alternativas. São estas: estruturas do governo, hospitais, instituições particulares, ONG ou instituições religiosas.

Recolhemos documentação sobre a problemática da saúde mental (estudos publicados, bibliografia e relatórios técnicos), e legislação e as políticas de saúde e mais concretamente as políticas de saúde mental em Moçambique e no Brasil nos séculos XX e XXI. É necessário perceber o discurso oficial sobre o campo mental, para compreender depois o campo do discurso leigo.

Identificámos elementos-chave nas duas localidades onde realizar o trabalho empírico, com quem tivemos reuniões, e realizámos entrevistas com essas entidades, quer do sistema oficial de saúde, quer do sistema tradicional e alternativo, incluindo os profissionais de saúde dos dois sistemas vigentes. Para além da recolha dos testemunhos dos dirigentes das instituições que lidam com a saúde mental e com a medicina tradicional, selecionámos profissionais/ /terapeutas que entrevistámos, profissionais da área da saúde mental e da área de medicina tradicional. Algumas entrevistas foram previamente marcadas antes das deslocações a Maputo e a João Pessoa, sendo a maior parte das restantes marcadas já no terreno através dos contatos que íamos estabelecendo. O trabalho de campo assentou em entrevistas em profundidade, dado que estas possibilitam o acesso ao universo de sentidos partilhados pelos sujeitos. A partir desses sentidos, enquanto manifestações discursivas individuais, podemos aceder à dimensão social, visto que eles se constituem reveladores da dimensão social e cultural do coletivo. Nos discursos procurámos perceber, a partir das narrativas de saúde e doença em geral e sobre doença mental, como é que se concebe o sistema de cuidados de saúde conhecido e como é ele mobilizado nas situações de experiência própria ou próxima e conhecida.

Recolhemos um conjunto de testemunhos sobre as racionalidades leigas e representações acerca da saúde mental e do sofrimento mental. Os discursos que recolhemos permitem-nos aceder a essas racionalidades enquanto modos de produção de sentidos sobre o sofrimento mental. As representações de doença mental estão povoadas de imagens mitificadas, enraizadas em conceções dominantes de períodos históricos anteriores. As racionalidades leigas que encontrámos incorporam várias formas de conhecimento (com as suas classificações, representações, saberes), provenientes de vários campos, onde se inclui a ciência a par da religião, da moral, da magia, da natureza, enfim, da cultura. Em suma, elas são plurais, integram discursos públicos (discursos difundidos publicamente, nos mass media) mas também privados (muito mais ligados às formas de entender, significar e lidar com o sofrimento mental que passam de geração em geração e se reproduzem na prática quotidiana, lugar onde os conhecimentos são convocados para produzir sentidos, estabilizar o mundo e dar lugar à interação).

As representações sociais sobre a doença mental têm uma conotação negativa precisamente pelo valor moral negativo que Ihes está associado, de falhas de caráter e também pelos defeitos físicos, que contribuem para a reprodução dos estereótipos estigmatizantes (Goffman, 1988). Existe uma conotação negativa associada à saúde mental, e a presença da Medicina Tradicional é central.

A gestão dos percursos terapêuticos é complexa e resulta da gestão dos saberes e dos poderes de os influenciar. Poderes estes que se jogam em vários campos - não apenas o da medicina oficial com os seus serviços e os seus profissionais, mas também o das relações interpessoais (familiares e de vizinhança e amizade, onde se estabelecem relações de entreajuda, mas também relações de controlo moral e social) e da vida comunitária onde se situam as redes pessoais e os recursos que escapam ao controlo da medicina (estratégias naturais, religiosas, mágicas, sobrenaturais, etc.). A medicina tradicional joga um papel crucial no domínio da saúde mental. As conceções tradicionais e culturais de doença mental têm levado à discriminação dos doentes mentais e, por vezes, a atendimentos desumanos (Misau, 2006a; Misau, 2006b).

Pensamos existir uma tendência para a prevalência do recurso aos modelos causais explicativos da saúde mental e do sofrimento mental baseados em conhecimentos e nas práticas tradicionais, o que pode refletir uma persistência na opção cultural associada a dificuldade de acesso a cuidados de saúde convencionais.

Esta pesquisa poderá contribuir para propor a reorganização das estratégias de promoção de saúde e envolvimento comunitário, reforçando a coordenação com as autoridades tradicionais locais; criação de estratégias conjuntas entre o governo e as autoridades tradicionais locais, aumentando assim a articulação entre estratégias e estruturas existentes.

Em termos de prevenção e de promoção, a tónica pode ser colocada no desenvolvimento do lado mais comunitário da sociedade de modo que se contrarie a tendência para o individualismo, isolamento e solidão.

\section{Dimensões de análise das entrevistas}

a) Leigos

I. A doença e a não-doença - categorias do pensamento leigo;

II. Taxonomias leigas para identificar o sofrimento mental/denominação da saúde mental e do sofrimento mental; 
III. Conceções subjacentes/explicação, sentidos. Identificar o problema, o que é feito para lidar com a situação, em que resulta;

IV. Formas de lidar com a doença mental e o sofrimento mental: os sistemas de cuidados, a esfera oficial, o sistema médico; a esfera da gestão e administração informal da doença mental: família, vizinhos, amigos, as relações de solidariedade da família, da vizinhança e dos amigos; os itinerários terapêuticos;

V. Relação do sofrimento mental com os espíritos;

VI. Recurso à medicina tradicional para tratar problemas;

VII. Opinião sobre como deve a sociedade, os serviços e os profissionais tratar estas situações.

b) Dirigentes/profissionais

I. Descrição do sistema de saúde mental em Moçambique;

II. Opinião sobre o sistema atual em funcionamento, porquê;

III. Necessidades neste campo;

IV. Como gostaria que ele fosse;

V. Articulação entre o sistema oficial e o sistema da medicina tradicional;

VI. Existência de sistemas formais de participação dos utentes ao nível da elaboração das políticas de gestão dos serviços. Existência de participação efetiva dos pacientes na saúde.

\section{O trabalho de campo}

Foram feitas duas deslocações aos dois campos de análise, Maputo em Moçambique (23 de março a 1 de maio) e João Pessoa no Brasil (13 de julho a 18 de agosto), durante o ano de 2014, para recolher dados para o estudo em epígrafe.

Houve um trabalho prévio de preparação da pesquisa - elaboração do projeto, pedido de apoio financeiro ao CEMRI-FCT (bolsa de licença sabática), contatos com as universidades em Moçambique e no Brasil, pedido de apoios institucionais com as universidades de acolhimento nos locais de trabalho de campo, criação de protocolos e cartas-convite, contatos com informantes privilegiados para marcação de encontros e pedidos de contatos para selecionar as pessoas a entrevistar, conceção e submissão do protocolo e pedido de autorização ao Comité Nacional de Bioética para a Saúde do Ministério da Saúde de Moçambique e Comitê de Ética em Pesquisa do Centro de Ciências da Saúde da Universidade Federal da Paraíba, através do Plataforma Brasil.

O trabalho de investigação decorreu em duas instituições de acolhimento, nomeadamente na Universidade Eduardo Mondlane, Faculdade de Letras e
Ciências Sociais, Centro de Análise de Políticas (CAP), em Maputo, e na Universidade Federal da Paraíba, Centro de Ciências Humanas e Letras, Departamento de Psicologia, no âmbito do Núcleo de Pesquisa "Aspetos Psicossociais de Prevenção e Saúde Coletiva", Programa de Pós-Graduação em Psicologia Social.

Em ambas as instituições de acolhimento foi realizado o trabalho de pesquisa na área da saúde mental e práticas alternativas.

Foram realizadas 21 entrevistas a leigos em cada uma das cidades (Maputo e João Pessoa), e entrevistado profissionais da saúde mental (psicólogos, psiquiatras e técnicos de psiquiatria), profissionais das medicinas tradicionais e práticas complementares e integrativas (médicos tradicionais em Moçambique e terapeutas alternativos e pais de santo, espíritas, pastores e rezadeiras em João pessoa) e dirigentes (diretores de departamento, coordenadores, vereador) (21 em Maputo e 22 em João Pessoa).

Para encontrar a amostra de 21 adultos leigos em cada uma das cidades, utilizámos uma amostra de conveniência em bola de neve, para a qual o investigador estabeleceu previamente o contato com alguns sujeitos identificados como membros do grupo que pretendia estudar.

Procurámos diferenciar essa amostra tendo em conta os critérios de inclusão: género, escalões etários, zona mais urbana e zona mais periférica, profissões, escolaridade e grupos sociais distintos (posições de classe).

Partimos de alguns indivíduos que aceitaram ser entrevistados e que conhecemos através das instituições onde desenvolvemos a pesquisa ou a partir de pessoas conhecidas que puseram a investigadora em contato com outras pessoas que também podiam responder à mesma entrevista. Temos também uma subamostra de familiares de doentes mentais e de pessoas que têm ou já tiveram algum tipo de distúrbio mental.

Este grupo restrito de pessoas, a que chamamos de amostra, não tem como finalidade ser representativo da população de ambas as cidades, sendo considerado um estudo de caso.

Durante o trabalho de campo foram realizadas diversas ações, nomeadamente: participação em seminários, observação de um grupo de terapia comunitária em João Pessoa com doentes mentais, realização de um grupo focal com seis médicos tradicionais em Maputo, encontros/reuniões com instituição de acolhimento e agendamento de entrevistas a pessoas de contato; psicólogos que aceitaram a entrevista a partir de dois contatos preestabelecidos ainda em Portugal; recolha de documentação e legislação; pesquisa e recolha bibliográfica; telefonemas, contatos e marcações de encontros/ /entrevistas; realização de entrevistas a leigos, a psicólogos, técnicos de psiquiatria, psiquiatras, médicos tradicionais, dirigentes, fitoterapeutas, espíritas, 
pastores de Igrejas Batistas, mães e pais de santo, rezadeiras; encontro com investigadores e docentes e outros académicos (profissionais que de certo modo trabalham nas áreas da saúde/doença mental e/ou nas áreas da medicina tradicional: sociólogos, psicólogos, pessoas da academia, investigadores que já tiveram alguma experiência interessante para relatar). Para além disso foram dadas aulas em formato de seminário para apresentar o projeto em curso nas universidades.

\section{Amostra}

Leigos em Maputo

\section{Homens}

Farmacêutico 23 anos

Técnico de farmácia 38 anos

Trabalhador lavandaria hotel 33 anos

Trabalhador lavandaria hotel 35 anos

Guarda vigilante 49 anos

Guarda vigilante 55 anos

Alfaiate 62 anos

Motorista 45 anos

Jornalista 54 anos

Assistente estagiário 28 anos

Docente universitário 68 anos

\section{Mulheres}

Professora universitária 33 anos

Diretora de departamento 42 anos

Escritora 59 anos

Logística num hotel 23 anos

Cozinheira 45 anos

Costureira 57 anos

Doméstica 32 anos

Doméstica 48 anos

Artesã (familiar de paciente de psiquiatria) 51 anos

Empregada doméstica 54 anos

Leigos em João Pessoa

\begin{tabular}{|c|c|}
\hline 9 Homens & 12 Mulheres \\
\hline Professor universitário 49 anos & Leiga com patologia mental 30 anos \\
\hline Leigo com patologia 49 anos & Professora liceu 39 anos \\
\hline Funcionário público 52 anos & Enfermeira 43 anos \\
\hline Trabalhador serviço limpezas 42 anos & Farmacêutica 65 anos \\
\hline Prontuário* 51 anos & Empregada doméstica 30 anos \\
\hline Estudante de educação física 37 anos & Farmacêutica 53 anos \\
\hline Policia rodoviária 48 anos & Trabalhadora serviço de limpezas 33 anos \\
\hline Rececionista hostel 53 anos & Rececionista 46 anos \\
\hline \multirow[t]{4}{*}{ Rececionista hostel 39 anos } & Rececionista 40 anos \\
\hline & Gráfica 35 anos \\
\hline & Costureira 61 anos \\
\hline & Dona de casa 37 anos \\
\hline
\end{tabular}

* Entrevistado usou este termo com referência ao seu trabalho com o inventário.

Profissionais/terapeutas e dirigentes em Maputo

\begin{tabular}{|c|c|}
\hline Homens & Mulheres \\
\hline Psicólogo 52 anos & Psicóloga 50 anos \\
\hline Psicólogo 61 anos & Psicóloga 35 anos \\
\hline Psicólogo 41 anos & Psicóloga técnica na associação de Amigos do Infulene \\
\hline Fitoterapeuta/espírita 66 anos & Psiquiatra no privado 62 anos \\
\hline \multirow[t]{6}{*}{ Curandeiro 42 anos } & Psiquiatra diretora de saúde mental 49 anos \\
\hline & Psiquiatra hospital do Infulene 39 anos \\
\hline & Psiquiatra diretora enfermaria psiquiatria do HCM 44 anos \\
\hline & Técnica de psiquiatria 23 anos \\
\hline & Médica tradicional presidente da cidade da Ametramo 54 anos \\
\hline & Médica tradicional presidente nacional da Ametramo 55 anos \\
\hline
\end{tabular}

Grupo focal de homens e mulheres/entrevista a médicos tradicionais com 6 elementos** 6 pessoas:

3 homens e 3 mulheres. 
Profissionais/terapeutas e dirigentes em João Pessoa

\begin{tabular}{|c|c|}
\hline Homens & Mulheres \\
\hline Vereador câmara municipal 43 anos & Psicóloga diretora CAPS 55 anos \\
\hline Pai de santo 49 anos & Enfermeira psiquiátrica 55 anos \\
\hline Arte terapeuta 42 anos & Psicóloga clínica CAPS 31 anos \\
\hline Psiquiatra do CPICS 40 anos & Psiquiatra 54 anos \\
\hline Curandeiro 42 anos & Psiquiatra diretora do hospital psiquiátrico 59 anos \\
\hline Pastor Igreja Batista 58 anos & Psicóloga coordenadora municipal saúde mental 38 anos \\
\hline Psiquiatra 47 anos & Psicóloga coordenadora estadual de saúde mental 37 anos \\
\hline \multirow[t]{7}{*}{$\begin{array}{l}\text { Presidente da associação de usuários do CAPS } \\
49 \text { anos }\end{array}$} & Psicóloga 42 anos \\
\hline & Terapeuta e diretora do CPICS 43 anos \\
\hline & Mãe de santo 55 anos \\
\hline & Mãe de santo 60 anos \\
\hline & Rezadeira 83 anos \\
\hline & Espírita 52 anos \\
\hline & Presidente federação espírita 61 anos \\
\hline
\end{tabular}

Comparando os leigos nos dois locais temos mais mulheres do que homens em João Pessoa e não foi possível diversificar muito o leque dos grupos sociais.

No caso dos profissionais e dirigentes, para Maputo temos uma amostra menos diversificada (2 diretores, 9 profissionais de saúde mental e 10 profissionais de medicinas alternativas e outras práticas complementares). Para João Pessoa temos 7 dirigentes/diretores, 5 profissionais de saúde mental, 7 profissionais de medicinas alternativas e outras práticas complementares e o presidente da associação de usuários do CAPS.

\section{Barreiras encontradas durante o trabalho de campo}

- Antes de chegar ao terreno foram difíceis os contatos com as instituições onde pretendíamos realizar as entrevistas para solicitar as cartas de cobertura;

- Houve uma grande espera na resposta dos comités de bioética para autorizarem o estudo;

- Já durante o trabalho no terreno, houve necessidade de reestruturação do protocolo para ser aceite e autorizado pelos respetivos comités de ética;

- Dificuldade no agendamento dos encontros e marcação das entrevistas com algumas pessoas. Em Maputo a maior dificuldade foi conseguir a marcação e aceitação da realização das entrevistas por parte dos dirigentes/decisores políticos, ao contrário do que aconteceu em João Pessoa, onde todos aceitaram colaborar na pesquisa e ajudaram muito a encontrar novos contatos;

- Confrontámo-nos com algumas desistências e abandono na colaboração para o estudo;
- Em Maputo houve alguma dificuldade em encontrar médicos tradicionais, uns não aceitaram, outros desmarcaram e não reagendaram, outros estão distantes geograficamente, o que dificulta a deslocação (e pagamento);

- Dificuldades nas deslocações e agendamento de encontros distantes do centro da cidade em locais periféricos;

- Dificuldade na comunicação por e-mail em Moçambique, meio ainda pouco usado; houve grande necessidade de realizar diversos telefonemas e ir ao encontro das pessoas pessoalmente para explicar o projeto e solicitar a adesão e colaboração no mesmo. Em João Pessoa a adesão tornou-se mais fácil; havendo menos desconfiança, a aceitação foi muito positiva (com exceção do líder da Igreja Universal do Reino de Deus, com quem não foi possível estabelecer contato).

\section{Resultados preliminares}

O que se entende por racionalidades de saúde e doença mental?

- Existe uma forte associação com termos comuns, terminologia utilizada para exemplificar ou fazer alusão ao fenómeno da loucura e da doença mental (relação com maluco em Maputo e com o termo doido em João Pessoa);

- Relação com problemas orgânicos, do corpo: (Maputo: resulta de choques, o organismo não dá conta, células que se regeneram, mau funcionamento de um órgão, lesão no cérebro, patologia, mal-estar mental; João Pessoa: a criança nasce com problema de formação no cérebro, outra forma é um trauma, ou se leva uma pancada na cabeça, ou um derrame, distúrbio neurológico das funções); 
- Em João Pessoa encontrámos uma forte associação com rótulos, termos psiquiátricos, taxonomia (depressão, transtorno obsessivo-compulsivo, esquizofrenia, retardado mental, pessoa depressiva, pessoa especial);

- Relação com preocupação, pensar muito, que provoca desequilíbrio, distúrbio, causa emocional (pensar muito, cansaço, preocupação, um distúrbio, pessoa não regula bem, não pensa bem, problema emocional mal resolvido);

- Relação com perturbação, não normalidade, problemas, consequência do stress, incapacidade que eu sinto em lidar com as coisas (Maputo: perturbação, cansaço, enfrenta problemas, doença mental é causada pelo stress, incapacidade em lidar com as coisas; João Pessoa: começa a ter as suas perturbações fora do seu quotidiano que a perturba, trabalho em excesso, falta de apoios, de atenção, pessoas com stress, nervoso, às vezes agride as pessoas);

- Relação com o seu estado de saúde, doença mental/a doença do próprio, episódio pessoal (Maputo: pessoa com doença mental vive num mundo de incompreensão e sei-o por experiência própria, eu chorava sozinho, às 12 horas ia na igreja - o sofrimento é a própria doença mental. Sofreu um acidente há 2 meses e anda muito atrapalhada, esquece-se das coisas, não está no seu estado normal, entra em stress; João Pessoa: pessoa fica bloqueada, não tem resposta, sente taquicardia, pressão cardíaca, momentos de solidão, tristeza, fica isolado, tem medo, habilidade de lidar com pessoas, angústias; três casos com transtorno bipolar, "a doença mental maltrata muito a gente e não é entendida pela própria família, taxam a gente de preguiçoso, não é que a gente não queira, a gente não pode"; passei por muita coisa, com 12 anos eu caí no hospital. Vários fatores de sofrimento, de angústia, muita angústia; depressão);

- Relação com a prevenção, com a saúde mental: (João Pessoa: saúde mental é a prevenção para impedir os outros males de chegar, é o equilíbrio, consigo olhar para o meu interior, e percebo-me, tenho uma noção de como eu me sinto);

- Provocado por drogas;

- Provocadas por espíritos e provocadas por seres humanos através da feitiçaria e magia (antepassados, manifestações como não-obediência dos rituais, os antepassados ficam revoltosos. Esse comportamento vai manifestar-se em alguns comportamentos anormais; quero que o meu negócio melhore, e tem de escolher alguém da família para prejudicar, nos os moçambicanos, 30 \% dos casos são isso. Se levares ao curandeiro de novo e a pessoa fica normal, doença mental é um espírito mau, são pessoas vítimas de obsessões, são pessoas obsidiadas, pessoas que estão a ser vítimas e atormentadas por espíritos obsessores; sofreu um feitiço, alguém atormentado por espíritos, um familiar, um antepassado fez e esses espíritos aparecem para atormentar a pessoa).

Em ambos os contextos as pessoas associam sofrimento mental e doença mental: uso de terminologias "populares" da linguagem comum, associação com maluquice e com doidice; problema orgânico, e uso de termos psiquiátricos; resultado de preocupações, de pensar muito; resultado de perturbação, não-normalidade, problemas, consequência do stress; relação com o seu estado de saúde, doença mental/ /a doença do próprio, episódio pessoal.

Em Maputo, em relação com consumo de drogas e sobretudo com espíritos e provocadas por seres humanos através da feitiçaria e magia.

Os discursos leigos são diferentes em Maputo e em João Pessoa e muito associados com o contexto sociocultural de cada uma das sociedades.

Uma mais tradicional, a africana, em que as causas do sofrimento mental e da doença mental surgem intimamente relacionadas com causas espirituais e de cariz religioso, e outra, a sociedade brasileira, apesar de periférica, mais ocidentalizada, onde os discursos já são mais biomédicos e usam terminologias biomédicas.

Discurso dos profissionais de saúde mental: psicólogos e psiquiatras/dirigentes

\section{Maputo}

Altera o comportamento normal 1

Desestabilizador, perturbador, incomoda 2

Tem muito sofrimento 2

Pacientes com depressão 1

Alteração do padrão normal 2

Incomoda mais os que estão por perto, os familiares

\section{João Pessoa}

Diferente de nós 1

Vem da correria, do consumo desenfreado

Causa desconforto

Foge dos padrões ditos normais, sai da normalidade

Danos no cérebro

Transtorno

Sofrimento

Perda do sentido da realidade

Perda da consciência

Incomoda mais os que estão por perto (familiares) 
Médicos tradicionais

Por causa dos espíritos maus
Porque alguém fez mal a essa pessoa
Feito algo a outra pessoa, uma maldade, a pessoa fez feitiçaria, está enfeitiçada
Porque foi roubar, então o dono fez um tratamento onde tinhas as coisas
Alcoolismo
Drogas
Problemas sociais
Conflitos conjugais, familiares
Stress devido à sobrecarga de trabalho
Ter nascido com essa doença/com deficiência

Terapeutas do CPICS e representantes dos centros espíritas

Terapeutas complementares
O que não é normal
Pode surgir de acontecimentos banais
Sofrimento
Prejuízo
Espíritas
Variedade de causas
Sofrimento
Transtornos

Os discursos dos profissionais de saúde mental são muito idênticos, usando mapas mentais semeIhantes e conceitos parecidos.

Os médicos tradicionais distinguem as diferentes causas e distinguem as causas médicas das espirituais, encaminhando os clientes para o hospital caso sejam causas não espirituais.

Os terapeutas complementares e os espíritas são também eles terapeutas, psicólogos e psiquiatras do sistema convencional, mas trabalham igualmente nestas esferas alternativas. No caso, um psiquiatra que faz acupuntura no CPICS e uma psicóloga que é líder e terapeuta num centro espírita.

\section{Recursos utilizados/Itinerários terapêuticos}

- Recurso à medicina tradicional:

Maputo: recorreu à medicina tradicional, o falecido pai usou espíritos, a convivência em casa escambou, a mãe foi ao curandeiro, o pai tinha de renovar, dar um banho, ele não renovou, aquilo estava a prejudicar a família; recorreu a uma curandeira e ao espiritismo; levaram ao curandeiro para a mãe falar com os espíritos, o curandeiro fez o que fez, a mãe recusou-se a ir, ficou doente e acabou por morrer. Trazem à psiquiatria não para curar mas para ficar abrigada e para os familiares não sofrerem.

João Pessoa: não foram encontradas referências à medicina tradicional.
- Uso de medicinas alternativas: Maputo: uso de remédios de ervanária; João Pessoa: alopatia, homeopatia, acupuntura, terapia para livrar dos traumas, e a parte religiosa, florais, terapias do centro de práticas integrativas e complementares, fitoterapia.

- Recurso às igrejas e centros espíritas: Maputo: os psicólogos sociais que estão mais próximos são as igrejas e ajudam os doentes mentais. Quem procura a igreja já não procura o curandeiro. Toda a gente já foi à medicina tradicional e ao curandeirismo;

João Pessoa: recurso às igrejas: evangélica, Igreja Universal do Reino de Deus, Batista, centros espíritas; a igreja ajuda; o CAPS ajuda; o lado espiritual ajuda; a astrologia ajuda (Leiga com patologia mental 30 anos).

Os itinerários terapêuticos são plurais em ambas as amostras.

Sistemas de Cuidados encontrados:

- Oficial/domínio da medicina convencional;

- Tradicional/domínio dos profissionais do dom e terapêuticas tradicionais e alternativas;

- Complementar e integrativo;

- Domínio da fé, da religião, espiritualidade;

- Esfera da gestão informal da doença. 


\section{Sistema oficial}

\section{Maputo}

- Os seus profissionais (psiquiatras, psicólogos, e técnicos de psiquiatria);

- As suas organizações (hospital geral, hospital psiquiátrico, enfermaria Hospital Central, urgências);

- As suas terapêuticas - sobretudo os medicamentos.

\section{João Pessoa}

- Os seus profissionais (psiquiatras, psicólogos, e enfermeiros, terapeutas);

- As suas organizações (hospital, CAPS, enfermaria, SAMU);

- As suas terapêuticas - terapia, medicamentos, ateliers, grupos de terapia comunitária.

\section{Sistema tradicional e complementar}

\section{Maputo}

- Médicos tradicionais;

- É referido o uso de medicinas alternativas;

- Recurso às igrejas evangélicas, Igreja Universal do Reino de Deus, Batista, centros espíritas.

\section{João Pessoa}

- Pais e mães de santo;

- Rezadeiras/benzedeira;

- São referidas terapêuticas complementares e integrativas; reiki, acupuntura, florais, ioga;

- Recurso às igrejas evangélicas, Igreja Universal do Reino de Deus, Batista, centros espíritas.

Os recursos e itinerários são plurais e diversificados. Em Maputo: Recurso à medicina tradicional. Em ambos os locais encontrámos o uso de medicinas alternativas, complementares e integrativas (mas mais usado em João Pessoa) e o recurso às igrejas evangélicas, Igreja Universal do Reino de Deus, Igreja Batista, também em ambos, os centros espíritas são mais frequentados no Brasil. As igrejas concorrem com a medicina convencional e com a medicina tradicional em ambos os contextos.

Existe um pluralismo médico, com particular ênfase na biomedicina, medicina tradicional e práticas terapêuticas associadas às igrejas.

\section{Referências bibliográficas}

ALVES, F. (2010), "Racionalidades Leigas sobre Saúde e Doença Mental - Um estudo no Norte de Portugal", in Fontes et al. (org) Desinstitucionalização, redes sociais e saúde mental: análise de experiências da reforma psiquiátrica em Angola, Brasil e Portugal, Recife, Editora Universitária UFPE, pp. 25-69.

ALVES, F. (2011), A doença mental nem sempre é doença: racionalidades leigas sobre saúde e doença mental - um estudo no norte de Portugal, Porto, Edições Afrontamento.

BARDIN, L. (2000), Análise de Conteúdo, Lisboa, Edições 70.

BASTIDE, R. e O. César (1956), "Pintura, loucura e cultura", Arquivos do Departamento de Assistência a Psicopatas do Estado de São Paulo 22, pp. 51-70.
BASTIDE, R. (1967), Sociologia das Doenças Mentais, São Paulo, Companhia Editora Nacional.

BASTIDE, R. (1978), o Candomblé da Bahia, São Paulo, Companhia Editora Nacional.

DALGALARRONDO, P. (2007), "Estudos sobre religião e saúde mental realizados no Brasil: histórico e perspectivas atuais", Revista de Psiquiatria Clínica, 34 , supl. 1 , pp. 25-33.

FERREIRA, L. O. (2013), "A emergência da medicina tradicional indígena no campo das políticas públicas", História, Ciências, Saúde-Manguinhos, 20 (1), pp. 203-219.

FORTUNATO DOS SANTOS, P. (2011), "Avaliação dos serviços de saúde mental em Moçambique", dissertação de mestrado em saúde mental internacional, Lisboa, Faculdade de Ciências Médicas, Universidade Nova de Lisboa.

GOFFMAN, E. (1988), Estigma - Notas sobre a manipulação da identidade deteriorada, 4. ${ }^{a}$ edição, Rio de Janeiro, Zahar.

GRANJO, P. (2009), "Saúde, doença e cura em Moçambique", in E. Lechner (org.), Migração, Saúde e Diversidade Cultural, Lisboa, ICS.

HONWANA, A. (2003), Espíritos vivos, tradições modernas: possessão de espíritos e reintegração social pós-guerra no sul de Moçambique, Lisboa, Ela por Ela.

IGREJA, V. (2009), "Agricultural cycle and the prevalence of posttraumatic stress disorder: a longitudinal community study in postwar Mozambique", Journal of Traumatic Stress, 22 (3), pp. 172-179. 
IGREJA, V. (2010), "The epidemiology of spirit possession in the aftermath of mass political violence in Mozambique", Social Science \& Medicine, 71, pp. 592-599.

KLEINMAN, A. (1984), Patients and healers in the context of culture. An exploration of the borderland between anthropology, medicine and psychiatry, University of California Press.

MEIRELES MENESES, M. (2000), "Medicina Tradicional, biodiversidade e conhecimentos rivais em Moçambique", Publicações da Oficina do Centro de Estudos Sociais da Faculdade de Economia da Universidade de Coimbra, CES, 150. Disponível em: http://www.ces.uc.pt/publicacoes/ oficina/150/150.pdf

MEIRELES, L. (2011), "A vivência da doença mental e a influência da Medicina Tradicional. O caso de Moçambique", dissertação de mestrado em Estudos Africanos, Lisboa, ISCTE.

MENESES, M. (2005), "Quando não há problemas, estamos de boa saúde, sem azar nem nada: para uma concepção emancipatória da saúde e das medicinas", in B. Sousa Santos (org.), Semear outras soluções: os caminhos da biodiversidade e dos conhecimentos rivais, Rio de Janeiro, Civilização Brasileira.

MISAU (2006a), Plano Estratégico 2006-2015, Maputo, MISAU.

MISAU (2006b), Estratégia e Plano de Acção para a Saúde Mental, Maputo, MISAU.
NHAMBIRRE, P. A. (2012), "Representações Sociais de Doença Mental: Um Estudo Exploratório com Leigos, Profissionais de Saúde e Curandeiros em Maputo", dissertação de mestrado em Psicologia Comunitária e Protecção de Menores, Lisboa, ISCTE.

NORDSTROM, C. (1997), A different kind of war story, Philadelphia, University of Pennsylvania Press.

PUSSETTI, C. (2006), "A patologização da diversidade. Uma reflexão antropológica sobre a noção de culture bound syndrome", Etnográfica, 10 (1), pp. 5-40. Disponível em: http://www.scielo.oces. mctes.pt/pdf/etn/v10n1/v10n1a01.pdf

WEST, H. (2005), "Working the Borders to Beneficial Effect: The Not-So-Indigeneous Knowledge of NoSo-Tradicional Healers in Northern Mozambique", in T. Luedke e H. West (orgs.), Borders and Healers: Broking Therapeutic Resources in Southeast Africa, Indiana, University Press.

WORLD HEALTH ORGANIZATION (WHO) (2000), General Guidelines for Methodologies on Research and Evaluation of Traditional Medicine, Geneva, WHO.

WORLD HEALTH ORGANIZATION (WHO) (2004), Global Status Report on Alcohol 2004, Geneva, WHO.

WORLD HEALTH ORGANIZATION (WHO) (2009), Country Cooperation Strategy 2009-2013 - Mozambique, Afro Library Cataloguing-in-Publication Data.

WORLD HEALTH ORGANIZATION (WHO) (2010), Mental Health and Development: Targeting people with mental health conditions as a vulnerable group, WHO Library Cataloguing-in-Publication Data.

Artigo recebido a 08/10/2015. Aceite para publicação a 04/12/2015.

Bárbara Bäckström (barbara.backstrom@uab.pt). Universidade Aberta, Departamento de Ciências Sociais e de Gestão \& Centro de Estudos das Migrações e das Relações Interculturais (CEMRI). Palácio Ceia, Rua da Escola Politécnica, 141, 1269-001 Lisboa, Portugal. 